\title{
Frequency and Characteristics of Mesiodens in Indian School Children: A Retrospective Radiographic Study
}

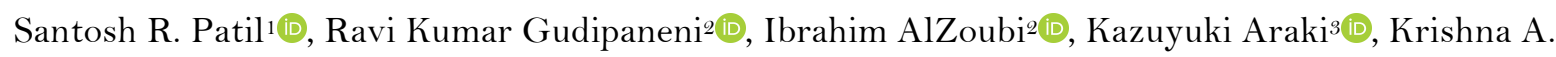
Rao'ㄹ, Mohammad Khursheed Alam(i)

${ }^{1}$ Department of Oral Medicine and Radiology, New Horizon Dental College and Research Institute, Chhattisgarh, India. 2Department of Preventive Dentistry, College of Dentistry, Jouf University, Sakaka, Kingdom of Saudi Arabia. ${ }^{3}$ Division of Radiology, Department of Oral Diagnostic Sciences, School of Dentistry, Showa University, Japan. ${ }^{4}$ Department of Orthodontics, College of Dentistry, Jouf University, Sakaka, Kingdom of Saudi Arabia.

Author to whom correspondence should be addressed: Dr Santosh R Patil, Department of Oral Medicine and Radiology, New Horizon Dental College and Research Institute, Chhattisgarh, India. Phone: +918281318181. E-mail: drpsantosh@gmail.com.

Academic Editors: Alessandro Leite Cavalcanti and Wilton Wilney Nascimento Padilha

Received: 11 March 2020 / Accepted: 15 May 2020 / Published: 26 May 2020

How to cite this article: Patil SR, Gudipaneni RK, AlZoubi I, Araki K, Rao KA, Alam MK. Frequency and characteristics of mesiodens in Indian school children: a retrospective radiographic study. Pesqui Bras Odontopediatria Clín Integr. 2020; 20:e0049. https://doi.org/10.1590/pboci.2020.092

\begin{abstract}
Objective: To determine the frequency and characteristics of mesiodens in Indian school children. Material and Methods: 1232 radiographs of patients attending the Department of Oral Medicine and Radiology of the age group of 4-15 years studied for the present retrospective study. The intraoral periapical radiographs and occlusal radiographs of the premaxilla were examined to determine the presence of mesiodens. The data regarding the presence of mesiodens, number, position, location on the arch, shape and associated complications were recorded. Results: Eleven patients had 14 mesiodens, with a frequency of $0.8 \%$. The ratio of boys to girls was 1.2:1. Maximum mesiodens observed in the age group of 7-9 years. Most of the mesiodens were conical in shape and found on the palatal side. Fifty percent of the mesiodens were unerupted. The majority of patients $(57.1 \%)$ had vertically positioned mesiodens. Midline diastema was the most common complication due to mesiodens (66.7\%). Conclusion: Routine check-up during the primary dentition and mixed dentition stages helps for early detection of mesiodens and thus preventing complications. Early identification is useful for planning comprehensive management, initiating proper consultation and referral for evaluation and treatment.
\end{abstract}

Keywords: Epidemiology; Cross-Sectional Studies; Tooth Abnormalities; Tooth, Supernumerary. 


\section{Introduction}

Various dental anomalies and malformations related to size, shape, number and eruption pattern of teeth may be encountered in children. Supernumerary tooth, also known as hyperdontia is an anomaly in many teeth, where one or more teeth develop beyond the normal series and may lead to alteration in the esthetics, eruption pattern of teeth or other related local complications [1].

Mesiodens is the most common type of supernumerary tooth present in conjunction with normal located, and it is located in the maxillary central incisor region [Q]. Bolk coined the term mesiodens in 1917 to represent an accessory or a supernumerary tooth, which is positioned mesial to both central incisors, in a normal or inverted position and having pegs shaped crown [3].

There are several ways of classifying mesiodens based on shape and occurrence. According to shape, mesiodens can be categorized as conical, tuberculated or molariform, and based on their occurrence, in the permanent dentition (rudimentary mesiodentes) or primary dentition (supplementary mesiodentes) [4]. Howard categorized supernumerary incisors as mesiodens, incisiform, invaginate or tuberculate and short, barrel-shaped and odontomes [5].

The prevalence of mesiodens oscillates between $0.15 \%$ to $2.2 \%$ as per the reports in the literature [6] Mesiodens are known to be associated with a variety of complications, like retention of primary teeth, closure of eruption path, crowding or midline diastema, axial rotation or displacement or inclination of erupted permanent incisors, resorption of the root of adjacent teeth pulpal necrosis, loss of tooth vitality and formation of the dentigerous cyst [7,8].

Mesiodens can occur individually or as multiples (mesiodentes), may be observed as a unilateral or a bilateral entity. A mesiodens may erupt in the oral cavity and do not erupt in some cases. These may be encountered during routine clinical and radiological examination of the maxillary anterior region by periapical, occlusal and panoramic radiographs $[9,10]$.

The objective of the present study was to determine the frequency and characteristics of mesiodens among a group of pediatric patients.

\section{Material and Methods}

\section{Study Design and Data Collection}

In the present retrospective study, a total of 1232 radiographs of the patients aged 4 to 15 years who attended the department of oral medicine and radiology evaluated. Radiographs of patients who attended for a routine visit or treatment of caries, gingival complaints, dental trauma, malocclusion and had patients with no previous history of extraction or tooth loss due to traumatic reasons, were evaluated in this study. Radiographs of patients with any congenital syndromes were not incorporated in this study.

\section{Data Collection}

The intraoral periapical radiographs and occlusal radiographs of the premaxilla were examined to determine the presence of mesiodens. An unerupted supernumerary tooth or tooth bud between the two central incisors, present in the midline of the maxilla either unilaterally or bilaterally was noted as a mesiodens. The data regarding the number, position, location on the arch, shape and other related complications were also documented from patient files.

Data Analysis 
Data were entered using SPSS 21.0 (IBM SPSS Inc., Chicago, IL, USA). Statistical analysis was carried out by applying Fisher exact test, and the statistical significance was set at $5 \%$ level of significance.

Ethical Aspects

Ethical clearance was obtained from the Institutional Ethical Committee of New Horizon Dental College and Research Institute (\# 8-20-3/40).

\section{Results}

Out of a total of 1232 patients examined in the study, 694 (56.3\%) were boys, and 538 (43.7\%) are girls. The mean age of total patients was $8.98 \pm 3.33$, in which the mean age of male patients was $9.25 \pm 2.65$ and mean age of female patients was $8.89 \pm 4.21$. The difference is found to be not significant $(\mathrm{t}=1.8326$, $\mathrm{p}>0.05)$. It has been noted that 11 patients had 14 mesiodens, with a frequency of $0.8 \%$. The ratio of boys to girls was 1.2:1. Maximum mesiodens was observed in the age group of 7-9 years. None of the patients had three or more mesiodens.

Table 1 shows that five males and four females were having unilateral, whereas only one of male and female were diagnosed to be having bilateral mesiodens. No association was observed between gender and types of mesiodens $(\mathrm{p}=0.9999)$.

Table 1. Distribution of mesiodens according to gender.

\begin{tabular}{lcccc}
\hline \multicolumn{1}{c}{ Gender } & \multicolumn{2}{c}{ Unilateral } & \multicolumn{2}{c}{ Bilateral } \\
& N & $\%$ & N & $\%$ \\
\hline Male & 5 & 60.0 & 1 & 50.0 \\
Female & 4 & 40.0 & 1 & 50.0 \\
$\quad$ Total & 9 & 83.33 & 2 & 16.67 \\
\hline
\end{tabular}

From the results of Table 2 , it is observed that, out of 14 mesiodens, $14.3 \%$ were seen in labial side followed by $71.4 \%$ in the palatal side and $14.3 \%$ were on the arch. A total of $71.4 \%$ of patients had conicalshaped mesiodens, followed by $21.4 \%$ had a supplemental shape, and $7.2 \%$ were found with tuberculate variety. Regarding eruption status, in $50.0 \%$ of patients, mesiodens was in un-erupted stage followed by $14.28 \%$ in erupted stage and $33.7 \%$ were in partially erupted stage. The majority of patients (57.1\%) had vertically positioned mesiodens, followed by $28.6 \%$ with inverted mesiodens, and $14.3 \%$ had horizontally positioned mesiodens (Table 2 ).

Table 2. Distribution of mesiodens according to location on the arch, shape, eruption status and position.

\begin{tabular}{lcc}
\hline \multicolumn{1}{c}{ Variables } & N & $\%$ \\
\hline Location & 2 & 14.3 \\
Labial & 10 & 71.4 \\
Palatal & 2 & 14.3 \\
On the Arch & & \\
Shape & 10 & 71.4 \\
$\quad$ Conical & 3 & 21.4 \\
Supplemental & 1 & 7.2 \\
Tuberculate & & 50.0 \\
Eruption Status & 7 &
\end{tabular}




\begin{tabular}{lll} 
Erupted & 2 & 14.3 \\
Partially Erupted & 5 & 35.7 \\
Position & & \\
Vertical & 8 & 57.1 \\
Inverted & 4 & 28.6 \\
Horizontal & 2 & 14.3 \\
\hline
\end{tabular}

A maximum of $57.1 \%$ of patients has midline diastema complication caused by mesiodens as compared to a minimum of $7.1 \%$ of each patient have resorption of adjacent teeth and asymptomatic complication caused by mesiodens followed by other complications (Table 3).

Table 3. Distribution of complications caused by mesiodens.

\begin{tabular}{lcc}
\hline \multicolumn{1}{c}{ Complications } & N & \% \\
\hline Midline Diastema & 8 & 57.1 \\
Delayed Eruption of Permanent Incisors & 2 & 14.3 \\
Axial Rotation or Inclination of Erupted Permanent Incisors & 4 & 28.6 \\
Resorption of Neighboring Teeth & 1 & 7.1 \\
Crowding & 2 & 14.3 \\
\hline
\end{tabular}

\section{Discussion}

A mesiodens is a supernumerary tooth located in the maxillary central incisor region. The frequency of mesiodens has been estimated to be different among different populations [12]. In a previous study, carried out in Saudi Arabia, to know the prevalence of some selected dental anomalies, mesiodens was observed to be less [10] whereas other authors found a higher prevalence, compared to that of the present study [13]. A previous study showed a low prevalence of mesiodens (1.4\%) in Indian population, which was more in comparison to the present study [14]. Although much higher prevalence has also been reported in a Turkish population, where a prevalence of $8.3 \%$ in the permanent dentition, $4.2 \%$ in the primary dentition and $87.5 \%$ in the mixed dentition was reported [15].

Supernumerary teeth in deciduous dentition are noted with an almost equal gender distribution. However, mesiodens occurs more frequently in boys than in girls, with the ratio being approximately 1.2:1 as reported in most of the studies [4,6,7,16,17]. In this study, a male: female ratio of $1.5: 1$ for the frequency of mesiodens was found, which is in agreement with previously mentioned studies, while other authors observed a disparity among the genders [13,15,18]. The differences in gender distribution may be due to the different sample sizes and the racial group that were examined. Maximum mesiodens was observed in the age group of 7-9 years, as this coincides with the eruption time of the maxillary central incisors. Thus, it is evident that most cases were discovered during this period.

According to the morphology, mesiodens can be classified into conical, supplemental and tuberculate type. Conical mesiodens is usually peg-shaped, developing with root formation ahead of or at an equivalent stage to that of the central incisor $[19,20]$. Tuberculate mesiodens is more commonly observed in permanent dentition and are usually unerupted. These type of mesiodens often interferes with the eruption of the central and lateral incisors [21]. A supplemental mesiodens resembles the tooth of the normal series and is more common in deciduous dentition. It rarely remains unerupted [19]. In the present study, the conical shape was found in most of the cases. It was previously reported that the prevalence of mesiodens was $0.8 \%$, and conical shape, palatal position and vertical orientation were common [9,21]. These findings were very similar to our present study. Furthermore, in the present study, unilateral or single mesiodens was present in the majority of 
cases. There were only 2 cases that had bilateral mesiodens. Not a single case with more than two mesiodens was observed in the present study. These findings are in conjunction with other similar findings, which reported one mesiodens in most of the reported cases $[6,9,14,18,21]$.

It is reported that most of the mesiodens remain unerupted and are discovered accidentally during radiological examination [21]. However, these supernumerary teeth have shown to erupt [14]. Inverted and transversely aligned mesiodens never erupt into the oral cavity [21]. These findings were in line with other studies mentioned in the literature. With regard to the direction of growth, the present study showed $57.1 \%$ vertically aligned mesiodens. This higher tendency of the vertical orientation of mesiodens is similar to the findings of previous studies that found $55.2 \%$ [6], 59.6\% [14], 62.8\% [21], 46\% [22], 62.5\% [23], and 67\% [24] of the supernumerary teeth in a vertical position axis.

A variety of clinical complications are caused by mesiodens such as delayed or non-eruption of maxillary incisors, interference with the positioning of the adjacent teeth, midline diastema, axial rotation or inclination of erupted permanent maxillary incisors, root resorption of adjacent teeth, dentigerous cyst formation, intraoral infection and mesiodens pulpitis [6,9]. In the present study, a maximum of $66.7 \%$ of patients had midline diastema complication due to mesiodens, followed by axial rotation or inclination of erupted permanent incisors (33.3\%). Complications such as dentigerous cyst, root anomaly, mesiodens pulpitis and intraoral infection were not observed in the present study, which was in contrast with the findings of some previous studies [20,23], which found dentigerous cyst in association with the mesiodens. When mesiodens have been impacted for a long period, they have a high risk of forming dentigerous cysts.

Very often, there can be confusion regarding whether and when to remove the mesiodens surgically, or whether to leave them in position and follow the patient radiographically at regular time intervals. Whatsoever be the management approach, early diagnosis is critical. Immediate surgical removal is indicated in younger patients soon after the diagnosis to prevent intra or postoperative complications. However, early detection does not call for immediate removal unless some pathological changes or interference is observed. Surgical removal should be avoided if the mesiodens is asymptomatic or when there are increased chances of damage to the developing permanent incisors. The role of the clinician in the successful management of a mesiodens is important because the earlier the diagnosis, minimal the future complications and the better is the prognosis.

\section{Conclusion}

Routine check-up during the primary and early mixed dentition stages help for early detection of mesiodens and other anomalies. Early diagnosis and treatment help in minimizing future complications and improving prognosis.

\section{Authors' Contributions}

\begin{tabular}{|c|c|c|}
\hline SRP & (iD) $0000-0003-0715-497 \mathrm{X}$ & $\begin{array}{l}\text { Conceptualization, Methodology, Investigation, Formal Analysis, Writing } \\
\text { Original Draft Preparation and Writing - Review and Editing. }\end{array}$ \\
\hline RKG & (iD) $0000-0003-3616-4042$ & Conceptualization, Formal Analysis and Writing - Review and Editing. \\
\hline IA & (iD) $0000-0002-8256-4541$ & Formal Analysis and Writing - Review and Editing. \\
\hline KA & (iD) 0000-0003-3524-5123 & Formal Analysis and Writing - Review and Editing. \\
\hline KAR & (iD) $0000-0001-8737-538 \mathrm{X}$ & Formal Analysis and Writing - Review and Editing. \\
\hline MKA & (iD) $0000-0001-7131-1752$ & Formal Analysis and Writing - Review and Editing. \\
\hline
\end{tabular}




\section{Financial Support}

None.

\section{Conflict of Interest}

The authors declare no conflicts of interest.

\section{References}

[1] Dalledone M, Tassi-Junior PA, Losso EM. Mesiodens surgery at deciduous and permanent dentition. RSBO 2015; 12(1):94-7.

[2] Akgun OM, Bayari SH, Ide S, Polat GG, Kalkhoran IO. Micro- and nanoscale structures of mesiodens dentin: combined study of FTIR and SAXS/WAXS techniques. Microsc Res Tech 2015; 78(1):52-8.

[3] Gorlin RJ, Goldman HM. Thoma’s Oral Pathology. 16th ed. St. Louis: The C. V. Mosby Co.; 1990.

[4] Russell KA, Folwarczna MA. Mesiodens - diagnosis and management of a common supernumerary tooth. J Can Dent Assoc 2003; 69(6):362-6.

[5] Howard RD. The unerupted incisor. A study of the postoperative eruptive history of incisors delayed in their eruption by supernumerary teeth. Dent Pract Dent Rec 1967; 17(9):332-41.

[6] Gündüz K, Celenk P, Zengin Z, Sümer P. Mesiodens: a radiographic study in children. J Oral Sci 2008; 50(3):287-91. https://doi.org/10.2334/josnusd.50.287

[7] Khandelwal V, Nayak AU, Naveen RB, Ninawe N, Nayak PA, Sai Prasad SV. Prevalence of mesiodens among six- to seventeen-year-old school going children of Indore. J Indian Soc Pedod Prev Dent 2011; 29(4):288-93. https://doi.org 10.4103/0970-4388.86369.

[8] Nagaveni N, Shashikiran N, Reddy VS. Surgical management of palatal placed, inverted, dilacerated and impacted mesiodens. Int J Clin Pediatr Dent 2009; 2(1):30-2. https://doi.org/10.5005/jp-journals-10005-1038

[9] Kim SG, Lee SH. Mesiodens: a clinical and radiographic study. ASDC J Dent Child 2003; 70:58-60.

[10] Osuji OO, Hardie J. Dental anomalies in a population of Saudi Arabian children in Tabuk. Saudi Dent J 2002; 14:1 1-4.

[11] Hurlen B, Humerfelt D. Characteristics of premaxillary hyperdontia. A radiographic study. Acta Odontol Scand 1985; 43(2):75-81. https://doi.org/10.3109/00016358509046490

[12] Buenviaje TM, Rapp R. Dental anomalies in children: a clinical and radiographic survey. ASDC J Dent Child 1984; 51(1):42-6.

[13] Järvinen S, Lehtinen L. Supernumerary and congenitally missing primary teeth in Finnish children. An epidemiologic study. Acta Odontol Scand 1981; 39(2):83-6. https://doi.org/10.3109/00016358109162264

[14] Patil S, Pachori Y, Kaswan S, Khandelwal S, Likhyani L, Maheshwari S. Frequency of mesiodens in the pediatric population in North India: a radiographic study. J Clin Exp Dent 2013; 5(5):e223-6. https://doi.org/10.4317/jced.51162

[15] Ersin NK, Candan U, Alpoz AR, Akay C. Mesiodens in primary, mixed and permanent dentitions: a clinical and radiographic study. J Clin Pediatr Dent 2004; 28(4):295-8. https://doi.org/10.17796/jcpd.28.4.0k2w2734hp76x541

[16] Zhu JF, Marcushamer M, King DL, Henry RJ. Supernumerary and congenitally absent teeth: a literature review. J Clin Pediatr Dent 1996; 20(2):87-95

[17] Tyrologou S, Koch G, Kurol J. Location, complications and treatment of mesiodentes: a retrospective study in children. Swed Dent J 2005; 29(1):1-9.

[18] Huang WH, T Sai TP, Su HL. Mesiodens in the primary dentition stage: a radiographic study. ASDC J Dent Child 1992; 59(3):186-9.

[19] Garvey MT, Barry HJ, Blake M. Supernumerary teeth - an overview of classification, diagnosis and management. J Can Dent Assoc 1999; 65(11):612-6.

[20] Primosch RE. Anterior supernumerary teeth - assessment and surgical intervation in children. Pediatr Dent 1981; $3(2): 204-15$.

[21] Mukhopadhyay S. Mesiodens: a clinical and radiographic study in children. J Indian Soc Pedod Prev Dent 2011; 29(1):34-8. https://doi.org/10.4103/0970-4388.79928

[22] Liu JF. Characteristics of premaxillary supernumerary teeth: a survey of 112 cases. ASDC J Dent Child 1995; $62(4): 262-5$.

[23] Asaumi JI, Shibata Y, Yanagi Y, Hisatomi M, Matsuzaki H, Konouchi H, et al. Radiographic examination of mesiodens and their associated complications. Dentomaxillofac Radiol 2004; 33(2):125-7. https://doi.org/10.1259/dmfr/68039278

[24] Roychoudhary A, Gupta Y, Prakash H. Mesiodens: a retrospective study of fifth teeth. J Indian Soc Pedod Prev Dent 2000; 18(4):144-6. 